\title{
Guidelines for Submission of Manuscripts
}

Contributors of manuscripts who closely adhere to the following guidelines will receive prompt and efficient consideration.

1. Copyright. The $J A A E$ is copyrighted. Authors are required to sign a release form, which will prohibit publication of material contained in the article elsewhere unless specific permission is granted by the editors.

2. Publication costs. Authors submitting manuscripts are expected to assume obligation for payment of page charges. Page charges currently are $\$ 65$ per page.

3. Format. Manuscripts should be typed on good quality $812^{\prime \prime} \times 11^{\prime \prime}$ paper with $1^{\prime \prime}$ margins. Use 11-point Times New Roman for manuscripts. Double-space all material throughout the manuscript, including the abstract, acknowledgments, footnotes, references, and tables. Type only on one side of the paper and do not use right-margin or full-margin justification. Use a separate cover page that lists authors and affiliations.

4. Abstract. On a separate page, include an abstract not to exceed 100 words, followed by no more than eight key words or short phrases, listed in alphabetical order.

5. Footnotes. Number footnotes consecutively throughout the manuscript. Type the content of the footnotes on separate pages placed immediately after the main text. Footnotes should not be used solely for citations or directives to other literature. Reference citations should be incorporated into the main text or into the text of the footnotes.

6. References. Place all references, cited in the text, alphabetized by author's last name on separate pages immediately after the footnotes. Citations may appear parenthetically or as part of the text. Within the text, use parentheses rather than brackets for citations. Spell out up to three authors' last names; for works with four or more authors, include only the first author followed by "et al." When citing a direct quote, include page number(s). Do not specify the publication year unless there is more than one reference by the same author(s).

7. Tables. Place each table on a separate page immediately after the references.

8. Figures. Place each figure, chart, or graph on a separate page immediately after the tables.

9. Mathematical formulations. Use Arabic numbers enclosed in parentheses placed flush left on the first line of the equation. Number equations consecutively throughout the manuscript. Indent the equation after the equation number. Punctuate all mathematical material.

10. Copies. Send three clean copies to:

Professors Charles B. Moss and James L. Seale, Jr., Editors

Journal of Agricultural and Applied Economics

Post Office Box 110245, University of Florida

Gainesville, Florida 32611-0245 


\section{Southern Agricultural Economics Association}

\section{Executive Committee}

President

Mary Marchant, University of Kentucky

President-Elect

Hal Harris, Clemson University

Past President

Eduardo Segarra, Texas Tech University

First Vice President

Hector O. Zapata, Louisiana State University

Second Vice President

Kimberly L. Jensen, University of Tennessee

Secretary-Treasurer

Robert G. Nelson and J. Walter Prevatt, Auburn University

\section{Membership and Subscription}

Members of the SAEA consist of individuals and organizations with a professional interest in agricultural economics. Membership includes a subscription to the Journal of Agricultural and Applied Economics. Calendar-year membership dues are $\$ 20$ and $\$ 10$, respectively, for regular and junior (student) memberships within North America (United States, Canada, Mexico and the Caribbean), and \$25 for international memberships. Payment must be made in U.S. dollars.

The annual subscription rate for libraries and other institutions is $\$ 30$ within North America and $\$ 40$ outside North America. Single copies of current or back issues are available at $\$ 15$ within North America or \$20 outside North America. Payment must be made in U.S. dollars.

Address all subscription, membership, and change-of-address information to Robert G. Nelson and J. Walter Prevatt, Secretary-Treasurer, SAEA, Department of Agricultural Economics and Rural Sociology, 203 Comer Hall, Auburn University, Auburn, Alabama 36849-5406. Telephone: (334) 844-5621 or (334) 844-5608, fax: (334) 844-5639, e-mail: rnelson@acesag.auburn.edu or jprevatt@acesag.auburn.edu, worldwide web site: http://www.ag.auburn.edu/saea/. 